\title{
Stigma in patients with early epilepsy: a national longitudinal study
}

\author{
NICKY BRITTEN, M E J WADSWORTH, AND P B C FENWICK \\ From the Medical Research Council National Survey of Health and Development, Department of Epidemiology \\ and Community Medicine, University of Bristol
}

SUMMARY Forty six cases of epilepsy were identified from the National Survey of Health and Development. An index of social visibility at school was constructed from teachers' reports of survey members' behaviour at 15 years of age. For the sample as a whole this index was significantly associated with poorer educational outcomes, after adjusting for social background and measured attainment, but was not associated with poor occupational achievement. However the index did not differentiate between epileptic and non-epileptic children. Although cases with epilepsy were shown to be more at risk of psychiatric disturbance, it is concluded that their lives were less disrupted than might have been expected, and that there is no evidence from this study that stigma affects the lives of those whose epilepsy was not complicated by other pathologies.

Like most serious illness in childhood, epilepsy is important not only for its immediate effects on the child's life but for its long term implications. In general, serious illness in childhood is potentially damaging to other aspects of the child's life as well as to health because of its effect on school progress and social contacts; but epilepsy has a complication of being a frightening illness both when it is observed and by repute. The child with epilepsy therefore experiences the development of a sense of "differentness" in the treatment of him or her by other people ${ }^{1}$ and comes to realise that this illness will impose limitations on certain choices in life, particularly occupation. Clinician's awareness of these potential problems may be seen in the general reluctance to make, and to make known to parents, the diagnosis of epilepsy in childhood. ${ }^{23}$ Thus it may be argued that what sociologists often call stigma develops both as a result of the public image of an illness and also because of the changes in the patient's self-concept and in the family's concept of the child that follow the first declaration of the diagnosis.

But over and above its image, epilepsy is very often a disabling condition, rendered especially disturbing because of its unpredictability. Other studies have already shown that people who have had, or who currently have, epilepsy seem more at risk of psychiatric disturbance and of unemployment, relatively low income and unstable job histories ${ }^{5}$ with poor job prospects ${ }^{6}$ than the general population. Yet apparently by no means all those with childhood epilepsy go on to suffer such problems. Harrison and Taylor ${ }^{5}$ conclude from a 25 year follow up study of epileptics that two thirds of their population "suffered minimal or no ill effect," and MacIntyre found in a survey of industry that $89 \%$ of men with epilepsy were "able to function without difficulty." And so in investigations of the effects of childhood epilepsy two questions predominate. To what extent does this illness have adverse social and psychological consequences? To what extent may any associated consequences be attributed either to the physical experience and damage of the illness or to its stigmatising effects?

Some aspects of these questions may be investigated with longitudinal data from a population sample, from which the same kinds of information have been collected on all members of the study, whether or not they were subsequently diagnosed as epileptic. We report on the later social development of children with epilepsy who were members of a national birth cohort. The same prospectively collected data are used to describe the extent and social consequences of epilepsy, and to investigate whether or not stigma plays an important part in reducing the life chances of those with epilepsy. We have therefore not been bound, as most other studies have, to consider possible stigmatisation only from the reports of sufferers. 


\section{Methods}

The Medical Research Council's National Survey of Health and Development is a longitudinal study of a national sample of children born in one week in March 1946. The sample comprises all legitimate single births to wives of non-manual workers and to wives of agricultural workers, and one in four births to wives of other manual workers, a total of 5362 children. These children have been studied at intervals of two years or less throughout childhood and adolescence and at somewhat longer intervals in adult life. Information has been collected on a wide range of medical, sociological, psychological, and education topics, and a full description of the study and a summary of work is given by Atkins and her colleagues. ${ }^{8}$ Information on the cohort's health and illness was collected at school medical examinations, which were carried out specifically for the study, and from hospital records followed up after reports of hospital admissions. Losses from the birth cohort have occurred through death and emigration, and in 1982, when those still resident in England, Wales or Scotland were last visited at home, $82 \%(n=3322)$ were contacted. Data reported here were collected while the cohort was aged 0-26 years.

\section{Results}

PREVALENCE, INCIDENCE, AND MORTALITY FROM EPILEPSY

Patients were included in the study if they had experienced two or more seizures, at least one of which had occurred after the age of 5, and if they had no evidence of acute illness accompanying the second or subsequent seizure(s). By the age of 26 years, 46 cases had been identified; of these, 42 had been confirmed by a hospital specialist and four by reports from a school doctor or general practitioner. ${ }^{9}$ Contact with the cohort 10 years later in 1982 suggests that a maximum of three cases may have been missed, but at the time of writing these have not been confirmed. All of the $\mathbf{4 6}$ patients with epilepsy had taken anticonvulsants continuously over long periods of time.

Cases in which there was no evident cause for the seizures, and no evidence of other central nervous system pathology, were graded as uncomplicated or idiopathic (30 cases), and the remaining 16 were graded as complicated, according to Graham and Rutter. ${ }^{10}$

Table 1 shows the incidence of epilepsy by age of onset. The figures given are population estimates, obtained by statistical weighting to compensate for the sampling procedure described above.

The present study is unusual in that it includes epileptics with age of onset ranging from the earliest years to the mid-20s, a fact which must be taken into account in the interpretation of findings about the effects of stigma. Children whose epilepsy was diagnosed before or during their school years (33 of the 46 cases) will already have lived a long time with the illness when they come to apply for jobs. They will thus have lived through adolescence with epilepsy, and we argue below that this is a time of greatest risk of stigma as well as vulnerability as far asformal qualifications are concerned. The 13 cases whose onset was diagnosed after 15 years may thus have improved life chances when compared with the cases diagnosed earlier in life.

\section{SCHOOL LIFE}

We have already compared the achieved educational level of children with epilepsy with those of two sets of controls, selected from the healthy members of the cohort and matched for sex, father's social class, and area of residence at age $4 .^{\circ}$ Educational qualifications of the complicated and uncomplicated cases taken together were significantly lower than those of their controls (Wilcoxon matched pairs test, $\mathrm{p}<0.05$ ), but this was not true for the uncomplicated group alone. In addition, those with early age of onset (before 15

Table 1 Incidence of epilepsy by age of onset*

\begin{tabular}{|c|c|c|c|c|c|c|}
\hline \multirow{2}{*}{$\begin{array}{l}\text { Age of onset } \\
\text { (years) }\end{array}$} & \multicolumn{3}{|l|}{ Number of cases } & \multicolumn{3}{|l|}{ Rate per $1000+$} \\
\hline & Uncomplicated & Complicated & $A \boldsymbol{l l}$ & Uncomplicated & Complicated & All \\
\hline $\begin{array}{c}0-4 \\
5-9 \\
10-14 \\
15-19 \\
20-26\end{array}$ & $\begin{aligned} 34 & (10) \\
6 & (3) \\
16 & (7) \\
17 & (8) \\
5 & (2)\end{aligned}$ & $\begin{aligned} 16 & (7) \\
14 & (5) \\
4 & (1) \\
2 & (2) \\
1 & (1)\end{aligned}$ & $\begin{array}{rr}50 & (17) \\
20 & (8) \\
20 & (8) \\
19 & (10) \\
6 & (3)\end{array}$ & $\begin{array}{l}2 \cdot 7,2 \cdot 9 \\
0 \cdot 5,0 \cdot 5 \\
1 \cdot 4,1 \cdot 4 \\
1 \cdot 4,1 \cdot 4 \\
0.4,0.4\end{array}$ & $\begin{array}{l}1 \cdot 3,1 \cdot 3 \\
1 \cdot 2,1 \cdot 2 \\
0 \cdot 3,0 \cdot 3 \\
0 \cdot 2,0 \cdot 2 \\
0 \cdot 1,0 \cdot 1\end{array}$ & $\begin{array}{l}4 \cdot 0,4 \cdot 2 \\
1 \cdot 7,1 \cdot 7 \\
1 \cdot 7,1 \cdot 7 \\
1 \cdot 6,1 \cdot 6 \\
0 \cdot 5,0 \cdot 5\end{array}$ \\
\hline $0-26$ & $78(30)$ & $37(16)$ & $115(46)$ & $6 \cdot 2,6 \cdot 6$ & $3 \cdot 0,3 \cdot 2$ & $9 \cdot 2,9 \cdot 8$ \\
\hline
\end{tabular}

*Figures are population estimates, and the unweighted numbers are in parentheses.

†The rates per 1000 are presented as maximum and minimum estimates, calculated on the basis of the size of the survey population at the beginning and end of each time period. 
years) were over-represented in the group without qualifications, but this was not the case for those with late onset. It is important, therefore, to ask why the early onset group seemed more vulnerable to low educational achievement, and so some details of children's school lives were examined, especially those thought likely to reveal evidence of stigmatisation.

Many aspects of the debate about the role of stigma as a source of influence in the lives of children with epilepsy depend on the notion that children with this illness are recognisably different in various ways. In this study, if any such differentiation has occurred it is likely to be reflected in teachers' reports on children's behaviour and attitudes to school work. No information is available about whether teachers knew of children's illnesses when these reports were made, but we guess that in many cases teachers must have been aware; and, as Wolff ${ }^{11}$ noted, "once a handicap is recognised allowances are generally made for the child's failures."

When cohort members were aged 15 years their form teachers (in most cases the teacher who knew the child best) rated them on a series of behaviour scales. ${ }^{12}$ Teachers rated cohort pupils regardless of type of school attended, and so the nine children with epilepsy who attended special schools (seven of the complicated and two of the uncomplicated cases) are also included in the following discussion. The social visibility of children with epilepsy, defined in this paper to mean their conspicuousness in the eyes of other people, should be apparent, if it exists, in their teachers' reports. If these children were found to be socially visible in this sense when compared with children who did not have epilepsy, it would be reasonable to conclude that this provided the foundation for possible stigmatisation. However, from what is known of the process, ${ }^{1-3}$ we could not conclude that this amounted in fact to stigmatisation.

Adolescence is a sensitive time, when children are especially anxious to conform with their age peers. Children who are different in some way usually react by trying particularly hard to be liked, either by their age peers, or by their teachers, and they are therefore likely to be more visible in a social sense than others as a result of their behaviour. Adolescence is also a time when teachers' and parents' expectations of children's behaviour and achievements are strongly associated with later educational success. ${ }^{12}{ }^{13}$ Such expectations and assessments by self and others are the basis for stigma, ${ }^{1-3}$ and therefore adolescence is a good time to look for evidence of stigma associated with epilepsy. It is also, in this study, a time when 34 of 46 children with epilepsy had already been diagnosed, and therefore data on teachers' views of cohort children's behaviour and educational chances collected at 15 years were examined. It is arguably these potentially damaging sources of stigma that are more important for the child's development than other sources of prejudice which may be less influential.

The 19 ratings that teachers made on each child were used to construct an index of social visibility of children at school at 15 years. This index was constructed by summing the number of reports of extreme behaviour for each child. The validity of this measure of visibility for the cohort as a whole was assessed in an attempt to discover whether visibility as defined here made any difference to the final educational qualifications of children of comparable ability and social background. Table 2 shows the relation between the visibility index and educational qualifications for the whole cohort. Those survey members with high visibility scores were more likely to have no qualifications and less likely to have high qualifications, and this result is statistically significant at the $1 \%$ level. A multivariate log linear analysis was then performed which took account of father's social class and the child's measured reading attainment at age 15 . The results showed that not only was visibility associated with attainment at age 15 (the same year in which the teachers' assessments were made), but that it was more strongly associated with final educational qualifications. Thus visibility as measured here does have some bearing on the progress of the whole cohort.

Having established the importance of the visibility score, it is then necessary to know whether it is associated with the poorer educational qualifications of the whole group with epilepsy. This was assessed first in a bivariate manner using the 19 individual ratings that comprised the social visibility index. These ratings were divided into those describing children's behaviour with others, their behaviour as individuals and their attitudes to work. Behaviour with others was concerned with roughness and with making friends, and on both indicators children with

Table 2 Educational qualifications of the subject and social visibility score

\begin{tabular}{lllll}
\hline Visibility score & $\begin{array}{l}\text { No } \\
\text { qualifications }\end{array}$ & $\begin{array}{l}\text { O Levels or } \\
\text { equivalent }\end{array}$ & $\begin{array}{l}\text { A Levels and } \\
\text { above }\end{array}$ & All subjects \\
\hline None & 516 & 378 & 531 & 1425 \\
Moderate & $27 \cdot 0 \%$ & $35 \cdot 3 \%$ & $36 \cdot 6 \%$ & $32 \cdot 2 \%$ \\
& 760 & 473 & 746 & 1979 \\
High & $39 \cdot 8 \%$ & $44 \cdot 1 \%$ & $51 \cdot 4 \%$ & $44 \cdot 6 \%$ \\
& 633 & 221 & 174 & 1028 \\
All subjects & $33 \cdot 2 \%$ & $20 \cdot 6 \%$ & $12 \cdot 0 \%$ & $23 \cdot 2 \%$ \\
& 1909 & 1072 & 1451 & 4432 \\
& $100 \cdot 0 \%$ & $100 \cdot 0 \%$ & $100 \cdot 0 \%$ & $100 \cdot 0 \%$ \\
\hline
\end{tabular}

$x^{2}=215 \cdot 9, \mathrm{df}=4, \mathrm{p}<0.001$. 
epilepsy were distinguishable from others. Those with epilepsy were more often rated as frightened of rough games when compared with others, especially if they had complicated epilepsy, and they were also less likely to make friends.

The behaviour and attitudes to work of children with epilepsy were more often reported as extreme by their teachers. They were more often reported as attention-seeking than others, but also as inclined to avoid attention. Similarly, they were over-represented among both those reported as daredevils and more fearful, over-competitive and diffident, gloomy and sad, timid and aggressive, and among those reported as disobedient and difficult to discipline. They were more inclined to be rated as unduly resentful of criticism, likely to daydream or be especially attentive, likely to be extremely energetic or always tired, to be poor and lazy workers or very hard workers, and more often they were seen as telling lies when compared with others. In other words, children with epilepsy were reported as different from others in these aspects of behaviour at school, and this is accounted for by the children with complicated epilepsy in almost all these behaviour ratings.

However, none of the associations between the individual ratings and epilepsy attained statistical significance except for the aggressiveness and attention-seeking scores. The findings are summarised in table 3 which shows the relation between epilepsy and the visibility score. A higher proportion of the children suffering from complicated, as compared with uncomplicated, epilepsy were rated as visible by their teachers. However, this relation does not attain statistical significance either.

To assess the importance of visibility for the children with epilepsy, another multivariate log linear analysis was performed which this time also included the distinction between children with and without epilepsy. The associations between visibility

Table 3 Severity of epilepsy and social visibility score

\begin{tabular}{lcccc}
\hline Visibility score & $\begin{array}{l}\text { Complicated } \\
\text { epilepsy }\end{array}$ & $\begin{array}{l}\text { Uncomplicated } \\
\text { epilepsy }\end{array}$ & $\begin{array}{l}\text { Rest of } \\
\text { cohort }\end{array}$ & All subjects \\
\hline None & 1 & 6 & 871 & 878 \\
& $10.0 \%$ & $26.1 \%$ & $22.3 \%$ & $22.3 \%$ \\
Moderate & 3 & 10 & 1989 & 2002 \\
& $30.0 \%$ & $43.5 \%$ & $50.9 \%$ & $50 \cdot 8 \%$ \\
High & 6 & 7 & 1049 & 1062 \\
& $60.0 \%$ & $30.4 \%$ & $26.8 \%$ & $26.9 \%$ \\
All subjects & 10 & 23 & 3909 & 3942 \\
& $100.0 \%$ & $100 \cdot 0 \%$ & $100.0 \%$ & $100 \cdot 0 \%$ \\
\hline
\end{tabular}

$\chi^{2}=2.78$ with 2 df (adding cols $1 \& 2$ ). Not significant. and attainment at 15 years, and between visibility and educational qualifications remained important, but there were no significant associations either between epilepsy and visibility or between epilepsy and qualifications. While this latter result may appear to contradict our earlier findings, two points should be borne in mind. Firstly, our earlier results were made with the use of matched controls. Secondly, and more important, is the fact that by 1972 sample loss (including mortality) for the complicated group was greater than that for the uncomplicated group. Of the 16 complicated cases, three had died and four could not be contacted at age 26 . Of the 30 uncomplicated cases, six had died and three were not contacted. It may be concluded that for the uncomplicated group at least, visibility was not a problem.

OCCUPATIONAL ACHIEVEMENT

We have already found that there is no evidence of poorer occupational achievement, as measured by social class at age 26 , for the uncomplicated group when they are compared with matched healthy controls selected from the cohort as described above. Those with early onset of epilepsy were more likely to be out of work and less likely to have non-manual jobs at age 26 than those without epilepsy, although this was not statistically significant. For the cohort as a whole, visibility was significantly associated with occupational achievement at age 26 (categorised as non-manual work, manual work or not economically active). Those with high visibility scores were more likely to have manual jobs than those with low or zero visibility scores.

A third log linear analysis was carried out to examine the associations between attainment at age 15 , the experience of epilepsy, father's social class, visibility at school, and occupational achievement at age 26 . There was no association between social class in adulthood and either epilepsy or visibility. The only association that remained significant was that between visibility and reading attainment at 15 years. This suggests that, for the uncomplicated group at least, visibility taken here as an indicator of stigma was not a serious problem.

\section{BEHAVIOUR DIFFICULTIES}

Two indicators of behaviour difficulties were used to compare children with epilepsy with others. First, data on delinquency in males up to age 21 years was investigated using official reports of offending. ${ }^{14}$ Of 21 boys with epilepsy, five were found to have been delinquent and all five had early onset of the illness. Although a higher proportion of those with epilepsy were reported as delinquent when compared with other boys, the difference did not reach statistical significance. 
The second indicator of behaviour was concerned with emotional disturbance. Reports of hospital admissions and of outpatient and general practitioner treatment for emotional disturbance, as well as self-assessments of stress collected while cohort members were aged 15-26 years, have been assessed by a psychiatrist and made into a scale of disturbance, insofar as treatment-seeking was concerned. On this scale seven $(18 \%)$ of 39 sufferers from epilepsy had had some medical (general practitioner or outpatient) treatment for emotional disturbance lasting a year or more, or had been admitted to hospital for psychiatric care, as compared with $6.8 \%$ of the 4572 men and women who had not had epilepsy. This is a statistically significant difference $\left(\chi^{2}=5 \cdot 85\right.$, with Yates' correction, and $\left.1 \mathrm{df} p<0 \cdot 05\right)$. Rates of emotional disturbance, thus defined, did not differ between those with complicated or uncomplicated epilepsy.

\section{Conclusions}

Data from a national birth cohort study have been used both to make a comparison between aspects of the school life and later achievements of children with epilepsy and those of other children, and to assess the role of social visibility at school. It was expected that the effects of stigma, if they could be detected, would be evident in our index of visibility. The present analysis has failed to demonstrate that social visibility is an important characteristic of the majority of children with epilepsy (the uncomplicated group) for either educational or occupational achievement at age 26 . In other words, there was no evidence for the damaging effects of stigma for the group with uncomplicated epilepsy: it was, by and large, not possible to draw conclusions about the complicated group because of small numbers. Thus, it may be concluded that those apparently least affected, in terms of the outcome indicators used in this study, are those whose epilepsy was uncomplicated and those whose epilepsy was first diagnosed after the age of 15 years. It comes as no surprise to find that the complicated group may be affected, but it goes against popular expectations to find that the majority of children with epilepsy were not apparently regarded as different by their teachers, and did not differ significantly from other children from comparable backgrounds in terms of their education and qualifications. Like Harrison and Taylor $^{5}$ and MacIntyre ${ }^{7}$ we also found epilepsy much less disruptive of achievement in education and occupation than might have been expected. However, the stress of such a chronic illness as epilepsy may be revealed by our finding that those with epilepsy were at greater risk than others of emotional disturbance in early adult life. We shall in due course have the opportunity to look at emotional stability again in later life.

Of course, these findings should not be seen as evidence that stigma is not to be found in this population. It may simply show that the outcome variables used here are not especially sensitive to stigma. An opportunity to look for possible stigmatisation will soon be provided by data recently collected on self-concept and on self assessment of life chances, as well as on periods of unemployment, collected on all cohort members when they were 36 years old.

But the evidence presented here is reassuring in that occupational achievement seems to have been relatively little affected by the experience of childhood epilepsy.

\section{References}

${ }^{1}$ Schneider JW, Conrad P. In the closet with illness: epilepsy, stigma potential and information control. Social Problems 1980; 28: 32-44.

${ }^{2}$ West PB. Acknowledging epilepsy: improving professional management of stigma and its consequences. In: Parsonage $M$, Grant $R$, Craig AG, Ward A, eds. New York: Raven Press, 1983.

${ }^{3}$ West PB. The physician and the management of childhood epilepsy. In: Wadsworth MEJ, Robinson D, eds. Studies in everyday medical life. London: Martin Robertson, 1976.

${ }^{4}$ Rutter M, Graham P, Yule W. A neuropsychiatric study in childhood. London: Spastics International Medical Publications, 1970.

${ }^{5}$ Harrison RM, Taylor DC. Childhood Seizures: a 25 year follow-up. Lancet 1976; i: 948-51.

${ }^{6}$ Rodin EP, Lennick P, Dendrill Y, Lin Y. Vocational and education problems of epileptic patients. Epilepsia 1972; 13: 149-60.

${ }^{7}$ MacIntyre I. Epilepsy and employment. Community Health 1976; 7: 195-204.

${ }^{8}$ Atkins E, Cherry N, Douglas JWB, Kiernan KE, Wadsworth MEJ. The 1946 British birth cohort: an account of the origins, progress and results of the National Survey of Health and Development. In: Mednick SA, Baert A, eds. Prospective longitudinal research: an empirical basis for the primary prevention of psychosocial disorders. Oxford: University Press, 1981.

${ }^{9}$ Morgan K, Britten N, Fenwick PBC, Britten H. Incidence of epilepsy in the first 36 years of life. In preparation.

${ }^{10}$ Graham P, Rutter M. Organic brain dysfunction and child psychiatric disorder. Br Med J 1968; ii: 695-700.

${ }^{11}$ Wolff S. Children under stress. London: Allen Lane The Penguin Press, 1969.

${ }^{12}$ Douglas JWB, Ross JM, Simpson HR. All our future. London: Peter Davies, 1968.

${ }^{13}$ Douglas JWB. The home and the school. London: MacGibbon and Kee, 1964.

${ }^{14}$ Wadsworth MEJ. Roots of delinquency. Oxford: Martin Robertson, 1979. 